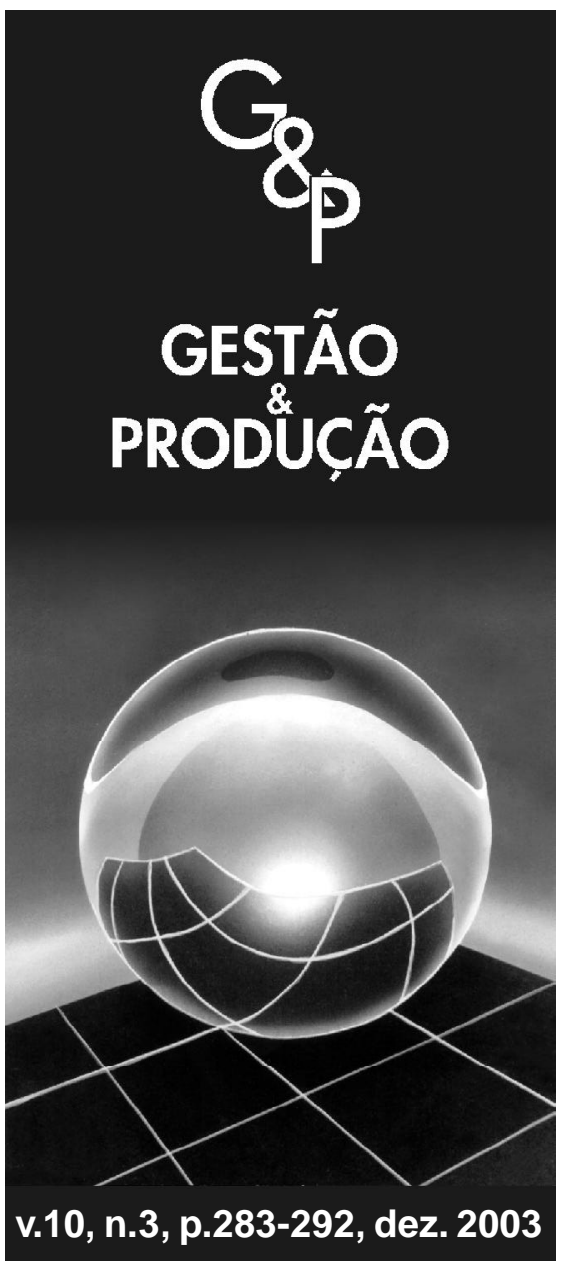

\title{
A RELAÇÃO UNIVERSIDADE-EMPRESA: COMENTÁRIOS SOBRE UM CASO ATÍPICO
}

\author{
Renato Dagnino \\ Erasmo Gomes \\ Grupo de Análise de Políticas de Inovação, \\ Departamento de Política Científica e Tecnológica, \\ Universidade Estadual de Campinas, \\ Rua João Pandiá Calógeras, 51, \\ CEP 13083-970, Campinas, SP, \\ e-mails: rdagnino@ige.unicamp.br, \\ erasmo@ige.unicamp.br
}

Recebido em 19/2/2003

Aceito em 12/11/2003

\section{Resumo}

O presente artigo refere-se a um caso de interação universidade-empresa considerado positivo pelos profissionais envolvidos - docentes e pesquisadores da universidade e técnicos da empresa -, tanto no que tange às atividades de pesquisa universitária e formação de recursos humanos quanto para a trajetória de capacitação tecnológica da empresa. Mais especificamente, aborda a realização de um projeto de pesquisa e desenvolvimento $(P \& D)$ envolvendo docentes e pesquisadores da Faculdade de Engenharia Mecânica da Universidade Estadual de Campinas (FEM/Unicamp) e de uma empresa multinacional do setor de autopeças, denominada, à época, Clark Equipments, atualmente, Eaton Trucks Corporation. $O$ artigo procura destacar aspectos relacionados aos antecedentes da interação, assim como aqueles relacionados à motivação que, no âmbito da empresa, levaram à realização do contrato com a universidade. Busca, ainda, conhecer a opinião da equipe técnica da empresa, bem como dos pesquisadores da Unicamp, acerca de suas implicações. Espera-se com a apresentação deste caso contribuir para melhor compreensão de uma questão presente na agenda atual da Política de Ciência, Tecnologia e Inovação: avaliar o que se pode realisticamente esperar das empresas multinacionais para o esforço nacional de desenvolvimento tecnológico.

Palavras-chave: interação universidade-empresa, pesquisa e desenvolvimento, política de ciência, tecnologia e inovação. 


\section{Introdução}

$\mathrm{E}$ ste trabalho aborda o tema da interação universidade-empresa focando um caso escolhido em um banco de dados elaborado pelos autores, contendo os projetos contratados por empresas e a Unicamp desde o ano de 1985.

Ele se refere a uma pesquisa desenvolvida durante o ano de 1996, contratada pela Clark Equipments, resultado de interação iniciada vários anos antes por professores da Unicamp da área que mais têm realizado projetos cooperativos com empresas privadas: a Faculdade de Engenharia Mecânica.

Sua apresentação se deve ao fato de ele ter sido considerado por esses professores um caso positivo de interação, no que diz respeito às atividades de pesquisa universitária e à formação de recursos humanos, e também por técnicos da empresa, em uma conjuntura em que a relação existente com a matriz norte-americana lhes permitiu seguir uma trajetória de capacitação tecnológica autônoma.

Talvez mais importante do que isso: acreditamos que esse caso pode ajudar a encarar com maior realismo uma questão presente na agenda atual da Política de Ciência, Tecnologia e Inovação. Nesse sentido, e apesar de as entrevistas que serviram de apoio à elaboração deste trabalho terem sido realizadas em meados de 2000 , em uma conjuntura bastante distinta, o fato de que uma positiva e promissora interação tenha sido abortada por simples decisão tomada pela matriz de uma empresa aqui sediada, consideramos que o caso ajuda a avaliar a contribuição que se pode realisticamente esperar para o esforço nacional de desenvolvimento tecnológico.

Embora o objetivo do estudo fosse identificar as motivações que no âmbito da empresa levaram à realização do contrato, e a opinião de seu pessoal acerca das implicações, o estudo buscou complementar a informação obtida por intermédio de contatos com os pesquisadores da Unicamp.

O material coletado nas entrevistas com professores e técnicos da empresa é utilizado ao longo do texto, em especial na seção "Considerações
Finais", a fim de ilustrar a dinâmica de interação ocorrida. Alguns trechos foram transcritos de modo a explicitar as motivações dos atores envolvidos, o que nos parece mais importante como subsídio para a análise da questão presente na atual agenda da Política de Ciência, Tecnologia e Inovação. Não obstante, eles também permitem inferir como se verificou o processo de capacitação (produtos desenvolvidos, busca e aquisição de conhecimentos, estrutura organizacional, constituição das equipes de desenvolvimento, etc.).

De modo a fornecer elementos para avaliar o caso estudado, envolvendo a Eaton Trucks Corporation (antiga Equipamentos Clark S.A.) e a Faculdade de Engenharia Mecânica da Unicamp, as seções que seguem apresentam uma breve caracterização do setor de autopeças e a trajetória institucional da empresa. A quarta seção, "A Interação da Clark com a Unicamp", apresenta um relato das atividades de cooperação desenvolvidas amplamente com base na opinião dos próprios atores. A quinta oferece uma síntese dos resultados do estudo, ou o que se poderia considerar uma lista de lições aprendidas com o caso, de forma a aumentar a chance de sucesso de oportunidades de interação entre universidade e empresa privada. A última seção procura mostrar como os resultados do estudo se relacionam às contribuições de outros autores que têm analisado a interação universidade-empresa.

\section{O setor de autopeças}

A história do setor está intimamente ligada à constituição da indústria automobilística no País, sendo marco de referência o ano de 1957, que representa o advento do primeiro ciclo de crescimento dessa indústria. Os encadeamentos proporcionados por essa indústria abarcam mais de 30 setores econômicos, que vão desde mineração, siderurgia, plásticos, vidros, pneus, produtos químicos, baterias, álcool e derivados de petróleo até serviços como distribuidores e revendedores, empresas de transporte e oficinas independentes. A indústria de autopeças ocupa uma posiçãochave entre fornecedores de insumos básicos e 
montadoras de veículos. Entre seus fornecedores se encontram as indústrias de plástico, siderurgia, componentes eletromecânicos, além de ampla gama de pequenas empresas de serviços de subcontratação.

A crise econômica do início dos anos 90 produziu forte transformação na indústria de autopeças no Brasil, tanto setorial quanto internamente às empresas. A reestruturação setorial baseou-se em forte processo de centralização do capital e enxugamento, pela realização de grande número de fusões e aquisições e pela saída de empresas. Internamente às empresas, o processo de reestruturação levou à redução dos níveis de hierarquia e do quadro de pessoal nas áreas produtiva e de gerência, bem como à terceirização (notadamente de serviços e em menor medida nas atividades produtivas). A reestruturação resultou em um setor mais concentrado, favorecendo empresas de maior porte (Furtado, 1992).

A produção do setor de autopeças tem por destino:

- as montadoras locais, que usam esses componentes na produção ou vendem-nos como partes originais no mercado de reposição;

- o mercado de reposição (exista ou não marca registrada do produto);

- a exportação.

As inovações de produto se caracterizam pela incorporação da microeletrônica em seus produtos (eletrônica embarcada), seguindo o padrão mundial. Também o emprego de novos materiais, sobretudo cerâmicos, e o aumento do uso de polímeros industriais podem ser observados.

No que se refere a inovações de processo, o setor foi um dos que mais investiu na racionalização da produção, seja via automação, seja pela adoção de métodos modernos de programação e controle da produção, como resposta à crise vivida pela economia do País e ao acirramento da concorrência internacional.

Em estudo sobre estratégias de modernização das empresas brasileiras, Fleury (1988) já destacava a proporção relativamente alta de empresas de autopeças que adotaram o que ele chama de estratégia de modernização sistêmica.
Trata-se de uma estratégia de modernização que visa à informatização, ao aumento da flexibilidade e à integração da empresa por intermédio da adoção de técnicas organizacionais (programas de qualidade, tecnologia de grupo, manufatura celular, just-in-time, etc.), podendo ou não haver apoio de sistemas de informação computadorizados.

A indústria de autopeças, especialmente as empresas líderes, tem posição-chave na dinâmica de difusão de novas tecnologias de processo no conjunto do setor metal-mecânico. As grandes montadoras e as grandes empresas químicas, metalúrgicas e de máquinas e equipamentos, juntamente com grande número de empresas fornecedoras grandes, médias e pequenas, conformam um tecido no qual as inovações se apresentam com elevado efeito a montante e a jusante (Furtado 1992).

$\mathrm{Na}$ indústria de autopeças é grande a heterogeneidade em relação aos produtos fabricados, ao porte e origem do capital das empresas e à capacitação técnica, produtiva e gerencial. Componentes centrais, como motores, transmissões, suspensões, sistemas de freios, etc., são produzidos pelas próprias montadoras e por alguns fornecedores cativos, empresas tecnologicamente mais avançadas, que produzem com qualidade, exigindo grandes investimentos em $P \& D$. Em produtos fundidos e forjados, o Brasil apresenta competitividade, decorrente da boa capacidade de manufatura das empresas, dos baixos custos dos produtos siderúrgicos básicos e da mão-de-obra (sendo um segmento intensivo em trabalho). $\mathrm{O}$ segmento de partes estampadas (como carrocerias, pára-choques e tanques de combustível), com produção pulverizada, apresenta configuração pouco compatível com as escalas requeridas para melhor desempenho competitivo.

Em produtos de plástico e de borracha a competitividade é ainda menor, por problemas de custo e qualidade. Finalmente, os produtos muito específicos para certos modelos (como assentos, painéis, pára-choques e espelhos) sofrem com a baixa escala e encontram dificuldades em ser produzidos com custos competitivos (Coutinho \& Ferraz, 1994). 
Ainda de acordo com Coutinho \& Ferraz (1994), para o setor de autopeças, que conta com expressiva participação de pequenas e médias empresas, a infra-estrutura educacional e de treinamento brasileira é extremamente frágil, embora instituições como o Senai tenham conseguido suprir com rapidez algumas das necessidades imediatas de treinamento dos trabalhadores quando da introdução de técnicas básicas de controle de qualidade. A gestão familiar, presente em número expressivo de empresas fornecedoras de autopeças, tem se tornado um obstáculo à modernização das empresas e ao estabelecimento de novas relações entre capital e trabalho.

\section{A empresa}

Produzir transmissões (caixas de câmbio) e engrenagens visando a atender à demanda potencial da indústria automobilística, que então começava a se implantar no Brasil, foi a principal motivação da matriz norte-americana Clark Equipment Company para implantar a empresa no País. A Equipamentos Clark Ltda. iniciou suas atividades no País no final dos anos 50, por intermédio da associação com uma pequena empresa nacional fabricante de engrenagens. Esta, contudo, foi rapidamente absorvida pelo primeiro grupo. Em novembro de 1959, com a inauguração da fábrica na cidade de Valinhos, SP, a Equipamentos Clark Ltda. transferiu-se da cidade de São Paulo, sua primeira localização.

Desde sua implantação até os anos 70, a empresa esteve envolvida em processo de crescente diversificação e verticalização de atividades produtivas, quando, então, passou a se concentrar em duas linhas básicas de produtos, desfazendose das demais. A partir dessa reestruturação, a Equipamentos Clark Ltda. passou a agregar, paulatinamente, a suas atividades de adaptação e nacionalização de produtos, atividades de $\mathrm{P} \& \mathrm{D}$ com ênfase em tecnologia de produto.

No início da década de 1980, a empresa começou a introduzir inovações organizacionais com base no modelo japonês como parte da estratégia para aumentar as exportações, mas continuava dependendo muito das montadoras, responsáveis por $70 \%$ de seu faturamento. Em 1994, a matriz decidiu que, para injetar capital na subsidiária brasileira, era necessário colocar ações da empresa à venda. $\mathrm{O}$ formato da operação foi inédito. Criou-se uma holding para a companhia, a Clark Automotive Products Corporation (CAPCO), com sede no Estado de Michigan (EUA).

De acordo com um ex-diretor da empresa: "nos separamos da matriz norte-americana, a Clark Equipment Co., porque nossos objetivos não eram mais os mesmos e tínhamos grandes oportunidades para a empresa no Brasil'. Participaram da negociação diversos fundos, entre eles o Merril Lynch e o Aliance. A CAPCO manteve um conselho administrativo formado por cinco americanos, ex-funcionários da Clark, e dois brasileiros.

Com a mudança, a Equipamentos Clark passou a deter a posição de maior fabricante independente de transmissões da América Latina, com mais de 5,8 milhões de unidades produzidas desde que iniciou a atividade fabril, em 1959. Cerca de $30 \%$ da produção era remetida ao exterior, em especial para os Estados Unidos e Argentina. No Brasil, seus maiores clientes eram a GM, a Ford, a Eaton do Brasil, a Volkswagen, a Maxion e a New Holland (Gazeta Mercantil, 2 jun. 1995).

A CAPCO existiu por dois anos. No final de 1995, iniciaram-se as negociações para compra da Equipamentos Clark Ltda., pela Eaton Truck Components, que foi efetivada em abril de 1996. A Eaton, uma das maiores fabricantes de câmbio do mundo, já era a principal cliente da CAPCO no Brasil, comprando o equivalente a $40 \%$ da produção de componentes. A Equipamentos Clark foi vendida por aproximadamente US\$ 138 milhões.

\section{A interação da Clark com a Unicamp}

O relacionamento da Clark com a Unicamp remonta a meados dos anos 80 . Naquela época, ele se baseava na execução de alguns pequenos projetos, pontuais e de curta duração. Um relacionamento mais sistemático aconteceria nos 
anos 90, como resultado do processo de planejamento estratégico da empresa.

$\mathrm{Na}$ gênese dessa interação, seja na primeira fase, mais esporádica, seja na segunda fase, mais sistemática, está o relacionamento pessoal, visto que a empresa contratava muitos engenheiros formados pela universidade. Ademais, o então diretor-presidente da empresa, engenheiro de produção formado pela Escola de Engenharia de São Carlos (EESC-USP), também havia sido professor da Faculdade de Engenharia Mecânica da Unicamp de 1969 a 1989.

Quanto ao processo que deu origem ao relacionamento com a universidade, o então gerente da Engenharia de Transmissões Leves comenta:

"O então diretor técnico da Clark, hoje professor dos cursos de extensão da Unicamp sobre Qualidade, sentindo a necessidade de tecnologias ditadas pelo mercado, começou a montar uma estrutura de $P \& D$ dentro da empresa. Tínhamos, até então, um departamento de engenharia de produto e um laboratório de testes, mas não havia um programa de $P \& D$ estruturado que, além de produtos, desenvolvesse tecnologia, know-how, que envolvesse outros campos de atuação, como manufatura, materiais, etc."

Naquela época, a matriz norte-americana estava reestruturando seus negócios, visando a fortalecer alguns segmentos de sua atuação e a abandonar outros. No segmento de transmissões, por exemplo, a empresa havia mantido apenas a planta brasileira. Segundo um dos dirigentes da empresa:

\section{"A filial brasileira não tinha nenhum suporte da matriz para tecnologia. Portanto, já em 1984-1985, teve início um investimento aqui no Brasil para criar suporte mínimo para se manter nos negócios. Essa situação gerou preocupação em relação ao futuro nosso negócio em termos de produto: o que deveria substituir a transmissão, que é uma tecnologia amadurecida bastante dominada?"}

Preocupada com as conseqüências desse processo de reestruturação da matriz, a diretoria da filial brasileira optou por realizar uma "auditoria tecnológica" na empresa, a fim de identificar seus pontos fortes e suas fragilidades, e definir em quais produtos ou linha de produtos investir ou desenvolver, visando a sua auto-sustentação tecnológica e financeira. Para assessorar nessa tarefa foi contatado um professor da Faculdade de Engenharia Mecânica da Unicamp.

Após um período de constantes reuniões com a equipe técnica e com o staff administrativo da empresa, utilizando metodologias de planejamento estratégico e de prospecção tecnológica, definiu-se uma carteira de dez projetos, sobre os quais se deveriam concentrar os esforços da empresa.

A percepção dos dirigentes da Equipamentos Clark Ltda. quanto a possíveis mudanças se concretizou em maio de 1994. A Clark Company colocou à venda a subsidiária brasileira por meio de oferta pública de ações - lançamento de 10 milhões de ações da Clark Automotive Products Corporation (CAPCO). O valor alcançado pela venda foi de aproximadamente US\$120 milhões. Ao constituir uma empresa independente da Clark Equipment, a subsidiária brasileira manteve sua antiga holding (CAPCO) e a concessão do nome para utilização no mercado brasileiro por três anos.

Segundo o ex-diretor da planta produtiva localizada em Valinhos, o motivo que levou à venda da subsidiária brasileira foi:

"a absoluta incompatibilidade entre as atividades da filial e da matriz. Enquanto a matriz fabricava veículos off road, a filial trabalhava com a indústria automobilística, fornecendo transmissões para carros de passageiros, picapes, caminhões e equipamentos agrícolas. Assim, a Clark Company decidiu concentrarse em seu negócio central, que é a produção de movimentadores de terra, e nada tem a ver com nosso negócio de transmissões."

Há, ainda, o fato de que, ao longo de sua atuação no País, a Equipamentos Clark Ltda. criou uma competência própria para execução de projetos adaptados à indústria automobilística local. Nesse sentido, o então diretor-presidente da empresa menciona que:

"com o tempo, desenvolvemos em Valinhos nosso setor de pesquisa; então, a empresa 
aqui já era totalmente independente da matriz, financeira e tecnologicamente. Temos total autonomia em pesquisa e projetos, $e$ tornou-se incômodo para a companhia investir alto em uma linha que não compartilha de sua linha de produção" (Gazeta Mercantil, 30 mar. 1994).

Foi em decorrência dessa reestruturação e da percepção de mudanças no planejamento que surgiu o "projeto de transmissão automática", que se tornaria posteriormente o pivô da cooperação futura com a Faculdade de Engenharia Mecânica da Unicamp. Contudo, se a universidade teve papel fundamental no delineamento do planejamento estratégico e na definição de prioridades de desenvolvimento tecnológico da empresa, sua atuação como principal parceira na execução do referido projeto não foi imediata. O parceiro inicial buscado pela Clark para execução do projeto de transmissão automática foi o Centro Tecnológico para Informática (CTI). Nas palavras de um dos dirigentes da empresa:

"A primeira fase do projeto foi basicamente buscar, na arena internacional, informações acerca de produtos desse tipo já desenvolvidos. Então, nos primeiros oito meses desse programa, a partir do início de 1991, um engenheiro recém-contratado trabalhou basicamente na obtenção desses dados. Conseguimos identificar as tendências e especificar três níveis de automação a serem introduzidos em nosso produto. A partir desse momento precisávamos de um parceiro com fluência no ramo da eletrônica - tínhamos consciência de que éramos uma indústria mecânica sem experiência em eletrônica. O Centro Tecnológico para Informática (CTI) estava realizando esforços no sentido de unir a eletrônica ao veículo. Então, inicialmente, essa etapa foi realizada em conjunto com essa instituição. Não tínhamos idéia de agregar a universidade. Um terceiro personagem seria uma outra empresa, tipo Boch ou Magnetti Marelli, do ramo automobilístico de eletrônica embarcada. Então, o conhecimento da equipe da Clark, em mecânica, do CTI, em informática e eletrônica, e dessa empresa, em eletrônica embarcada, formou a base do programa de pesquisa."

Após trabalhar com o CTI por aproximadamente um ano, a Clark decidiu interromper as atividades conjuntas com instituição. Isso se deveu a um entendimento mais preciso acerca da complexidade do projeto e da perspectiva multidisciplinar que o mesmo encerrava, que não estavam sendo suficientemente contempladas. Como consequiência, buscou-se a Faculdade de Engenharia Mecânica da Unicamp. Quanto à tomada de decisão para envolver a Unicamp no projeto, o entrevistado comenta:

"A universidade se dispôs a reunir um grupo envolvendo pessoas da engenharia elétrica, na área de controles elétricos, e de software, e fez uma proposta à Clark. Nós achamos que valeria a pena apostar, uma vez que estaríamos agregando uma equipe de altíssimo nivel, com doutores, mestres e graduandos, que dificilmente poderíamos contratar aqui na empresa, e também poderíamos contar com os laboratórios da universidade e com os nossos. Por outro lado, tínhamos noção da dificuldade que seria realizar um trabalho com a universidade, porque o foco do pesquisador universitário é diferente do nosso; nós estamos visando a um mercado, temos um plano objetivo de tempo, que nem sempre o pessoal da universidade tem. Mas resolvemos apostar..."

Segundo o gerente da Engenharia de Transmissões Leves da Clark, o projeto apresentou vários desafios e ganhos tecnológicos, tanto para a empresa como para a universidade:

"Foi possível desenvolver uma série de tecnologias de medição e de aquisição de dados de controle, que ninguém conhecia no início. Nós formamos um know-how aqui. O pessoal da universidade também cresceu, pôde aplicar uma série de conceitos, construímos uma bancada que simula com bastante precisão o comportamento de um veículo. Nessa bancada, desenvolvemos os controles - acelerador, freio e embreagem -, realizamos medições e aprendemos a controlar o sistema. 
Enfim, construímos e utilizamos para ensaio o primeiro protótipo. E, a partir de então, pudemos pensar em um protótipo para desenvolvimento, uma vez que a tecnologia do protótipo funcional estava dominada."

Da perspectiva da universidade, o projeto de transmissão automática desenvolvido em cooperação com a Clark possibilitou a elaboração de trabalhos visando à obtenção de títulos de doutorado e mestrado pelos alunos envolvidos, várias publicações e apresentação de trabalhos em eventos da área.

Por conta de novas mudanças nos rumos da empresa - a Equipamentos Clark foi adquirida pela Eaton Truck Components em negociação que teve início no final de 1995 e se concretizou em abril de 1996 -, o projeto foi interrompido. Segundo um dos dirigentes da empresa, a Eaton estava executando, por intermédio de seu centro de $\mathrm{P} \& \mathrm{D}$, um projeto bastante semelhante ao desenvolvido pela Equipamentos Clark. Para dar prosseguimento àquele, a nova proprietária da empresa decidiu interromper o projeto brasileiro.

Ainda de acordo com um dos dirigentes da empresa, a idéia dos coordenadores do projeto, quando nas mãos da Clark, era dar continuidade ao contato com a Unicamp por elaboração de "termos aditivos pequenos", para alguns desenvolvimentos específicos. Como balanço geral, a empresa considerou que o projeto foi bemsucedido, embora não tenha sido totalmente finalizado e apesar de se ter excedido o prazo, em razão de atrasos por parte da universidade.

\section{Síntese dos resultados: lista de lições aprendidas do caso para a interação}

A realização da pesquisa que deu origem a este trabalho permitiu identificar uma série de características pouco usuais do caso estudado, a qual foi responsável pelos êxitos e pelos fracassos observados. $\mathrm{O}$ fato de muitas delas, em especial as que se devem à origem do capital da empresa, não terem sido consideradas desde o início da pesquisa parece ter ocorrido, por um lado, por elas não terem sido destacadas por professores e técnicos entrevistados e, por outro, porque a bibliografia que trata da relação universidadeempresa no Brasil, e com mais razão nos países avançados, não aborda casos como este, em que o parceiro privado é uma multinacional sediada no país em que se verifica a interação.

Essas características, que podem ser sintetizadas como a seguir, configuram um tipo de lista de lições aprendidas do caso, a ser considerada pelas equipes universitárias quando da seleção de oportunidades de interação com empresas privadas. São elas:

- relacionamento da Clark com a Unicamp, que se iniciou em meados dos anos $80 \mathrm{e}$, em meados dos anos 90, deu origem ao caso estudado;

- a empresa apresentou crescimento continuado nesse período, em função de condições de mercado favoráveis;

- desde o início houve um relacionamento pessoal entre a empresa e a universidade, que envolvia seu diretor-presidente e outros dirigentes que, inclusive, haviam sido professores da Faculdade de Engenharia Mecânica;

- a contratação de vários engenheiros ali formados certamente facilitou a relação universidade-empresa privada e a execução de trabalhos conjuntos, seja pelo nível técnico existente no âmbito desta, seja pela facilidade ainda maior de transferir os resultados da pesquisa desenvolvida;

- a Clark, em função de seu status de filial de uma empresa estrangeira, possuía o que se pode chamar de "cultura inovativa", que favorecia a valorização da pesquisa universitária como fonte de resultados economicamente viáveis;

- adicionalmente ao anterior, o fato pouco usual de a matriz e a filial fabricarem produtos distintos - veículos off road e transmissões para a indústria automobilística e de a matriz não deter tecnologia para transferência, enquanto a filial possuía 
autonomia suficiente para buscar parceiros nacionais para desenvolvê-la;

- a concepção da pesquisa foi resultado de uma interação com a universidade por meio de um processo conjunto que, utilizando metodologias de planejamento estratégico e de prospecção tecnológica, definiu uma carteira de projetos prioritários;

- o caso estudado decorreu de um fator estranho às atividades de $\mathrm{P} \& \mathrm{D}$ e manufatura anteriores, associado a uma mudança na estratégia da empresa, que a forçou a desenvolver um projeto orientado à fabricação de um produto, pode-se dizer, inteiramente novo, para o qual não possuía capacitação suficiente;

- a decisão de envolver a universidade deu-se posteriormente a uma tentativa de interação com um instituto de pesquisa que não possuía capacidade em todo o espectro multidisciplinar necessário para a concepção do novo produto;

- a empresa abrigava uma equipe de alta capacitação tecnológica (e mesmo experiência em pesquisa científica), além de possuir capacidade de engenharia de produto para, a partir do resultado da pesquisa (o primeiro protótipo), chegar ao produto desejado;

- o alto grau de complementaridade das capacidades dos parceiros decorria da familiaridade dos professores da FEM, também pouco usual em nosso meio, com o ambiente empresarial;

- dada a originalidade do produto - transmissão automática - a que se destinava a realização da pesquisa cooperativa, determinada pelas características pouco comuns do caso estudado, ela foi bastante funcional para as atividades corriqueiras da universidade (realização de pesquisas de doutorado e mestrado, publicações, etc.);

- apesar de o ambiente da universidade e seu modo de operação serem conhecidos dos dirigentes da empresa e de a equipe do projeto estar familiarizada com o ambiente empresarial, ocorreu certo irrealismo na fixação dos prazos, que não foram cumpridos à risca pela universidade (embora seu desempenho tenha sido avaliado positivamente pela empresa);

- com a venda da empresa, as atividades conjuntas com a universidade foram descontinuadas, uma vez que dois dos fatores que as motivaram deixaram de existir: o novo grupo proprietário operava numa linha de produtos distinta e os centros de $\mathrm{P} \& \mathrm{D}$ estavam localizados nos Estados Unidos.

\section{Considerações finais}

O estudo de caso aqui relatado possibilitou, por um lado, melhor compreensão do comportamento dos professores da universidade, dos técnicos da empresa privada e das diferentes percepções que eles têm sobre os processos de interação. Por outro, permitiu conhecer alguns dos impactos que esses processos promovem na universidade e nas empresas e explorar suas prováveis tendências.

Os impactos positivos mencionados pelos professores - a possibilidade de obterem novos conhecimentos e de repassá-los aos alunos, o aumento do volume de recursos financeiros e a possibilidade de renovar as linhas de pesquisa existentes - e pelos técnicos da empresa - desenvolvimento de know-how próprio - corroboram a importância do caso estudado.

Isso levou ambos - por ocasião das entrevistas realizadas - a recomendar um aumento no número de projetos realizados em cooperação, sobretudo em uma conjuntura como a que já se prenunciava e que veio a se confirmar, de crescente privatização das empresas estatais.

O fato de os professores da Unicamp possuírem alta titulação acadêmica foi um fator freqüentemente citado pelos técnicos da Clark como importante para explicar o interesse da empresa e o sucesso da interação. Isso apesar de autores como Castro (1993) e Perre (1995) concluírem que o alto grau de titulação não é um imperativo, mas o que em seus estudos é considerado pelos entrevistados "excelência acadêmica". De qualquer forma, também no caso estudado o 
início da relação dependeu dela, porque é a "excelência acadêmica" que permite ao empresário/cliente localizar o pesquisador e conferir confiabilidade e respeitabilidade à atividade de pesquisa cujo financiamento propõe a seus pares.

O empenho dos professores, essencial no caso estudado, é corroborado por autores como Dierdonck et al. (1990), ao mencionar que "muitos professores têm sido os únicos responsáveis pelas interações com o meio externo".

Adicionalmente, o fato de a relação entre a FEM e a Clark ter sido considerada um caso atípico também reforça a opinião emitida por Dierdonck et al. (1990), ao afirmar que: "não há uma clara definição do papel dos escritórios [de contratos] na estratégia de pesquisa da universidade, e não há consenso sobre quais tarefas estes devem desempenhar”. De fato, na opinião dos professores da Unicamp, é bastante tímido o desempenho dos mecanismos institucionais de enlace.

Também corroborando as conclusões de autores como Stefanutto (1995) e Quirino (1993), em estudos realizados sobre outras instituições de ensino e pesquisa, no caso estudado foi destacado o papel dos alunos de graduação e pós-graduação para o sucesso da interação.

Ainda corroborando autores como Etzkowitz (1994) e Webster (1994), no caso estudado, a informação coletada enfatiza a necessidade de que a cooperação universidade-empresa não fique restrita às atividades de pesquisa propriamente ditas. Consultoria, prestação de serviço e outras atividades aparentemente "menos nobres" também representam oportunidades de interação, ao mesmo tempo em que ressaltam a complexidade dos processos de interação; inclusive porque delas derivam, muitas vezes, projetos de pesquisa de caráter institucional e mais duradouros.

Nesse sentido, embora não caiba falar em "Segunda Revolução Acadêmica", como a que aludem esses autores no caso das universidades brasileiras, o contato com os professores envolvidos no caso estudado evidencia preocupação em buscar um novo posicionamento da universidade em relação à sociedade. $\mathrm{O}$ papel que as empresas privadas ou privatizadas podem desempenhar nos processos de interação é visto como dependente de sua disposição em intensificar seus esforços em atividades de pesquisa e desenvolvimento intra e extramuros, em um contexto aparentemente nem sempre favorável. $\mathrm{O}$ abandono pelo Estado de algumas funções de estímulo ao desenvolvimento de $\mathrm{P} \& \mathrm{D}$ também é visto com preocupação.

Essas preocupações encontram eco na literatura estrangeira recém-citada acerca do modelo da Hélice Tripla (universidade-empresa-Estado), que vem reabrindo o debate quanto à estruturação de políticas públicas de $\mathrm{C} \& \mathrm{~T}$ ao propor uma relação dinâmica entre o Estado, a ciência realizada na universidade e a tecnologia desenvolvida na empresa. E, também, com os aspectos destacados há duas décadas na literatura latinoamericana, com a formulação conhecida como o "triângulo de Sábato", que mostrava como os vértices desse triângulo (universidade, Estado e empresa privada) se encontram desconectados nesses países (Sábato, 1994).

Para alguns dos professores, a fim de que a ciência produzida na universidade possa ser utilizada e transformada em tecnologia nas empresas, será necessário maior estímulo governamental para que as instituições de pesquisa e as empresas se inter-relacionem de forma a cumprir seu papel em um verdadeiro "sistema de inovação".

Caberia, portanto, ao Estado brasileiro, tal qual proposto por Sábato (1994), como função do vértice superior do triângulo, a instauração de mecanismos eficazes de interação entre a base científica criada nacionalmente e os atores sociais capazes de transformá-la em alavanca do desenvolvimento econômico e social.

Mas, como concluiu um dos entrevistados:

“...quando a globalização leva a um processo de privatização que desemboca na transnacionalização das empresas estatais e no abandono de suas atividades de $P \& D$ $e$, ao mesmo tempo, à aquisição de empresas nacionais, de modo semelhante ao que aconteceu com a Clark, é pouco provável que aumente a interação universidadeempresa..." 


\section{Referências Bibliográficas}

CASTRO, M. H. M. Estudo dos Centros de Excelência: Departamento de Engenharia Mecânica da Universidade Federal de Santa Catarina. Cadernos de Gestão Tecnológica, 4. São Paulo: NPGCT/ USP, 1993. $49 \mathrm{p}$.

COUTINHO, L.; FERRAZ, J. C. (Coord.). Estudo da competitividade da indústria brasileira. Campinas: Papirus/Editora da Unicamp, 1994. 510 p.

DIERDONCK, R. et al. University-industry relationship: how does the Belgian academic community feel about it? Research Policy, 1990.

ETZKOWITZ, H. Academic-industry relations: a sociological paradigm for economic development. In: LEYDERSDORFF, L.; VAN DEN BESSLAAR, P. Evolutionary economics and chaos theory: new directions in technology studies. London: Pinter Publishers, 1994. p. 139-151.

FLEURY, A. C. C. Impactos sobre a organização do trabalho, emprego e renda na indústria metalmecânica. São Paulo: Poli-USP, 1988. Mimeo.

FURTADO, A. (Coord.). Capacitação tecnológica e competitividade: uma abordagem setorial e por empresas líderes. Campinas: IPEA/PNUD/DPCT, 1992. (Relatório de pesquisa.)
GAZETA MERCANTIL. São Paulo, 30 mar. 1994. GAZETA MERCANTIL. São Paulo, 2 jun. 1995.

QUIRINO, T. R. O programa de soja na universidade Federal de Viçosa. Cadernos de Gestão Tecnológica, 7. São Paulo: CYTED/NPGCT/USP, dez. 1993.

SÁBATO, J. El origen de algunas de mis ideas. In: Repensando la política tecnológica: homenaje a Jorge Sábato. Buenos Aires: Ediciones Nueva Visión, 1994. p. 103-114.

STEFANUTO, G. N. Los límites del éxito de la investigación académica en el ambiente industrial. In: VESSURI, H. (Org.). La academia va al mercado: relaciones de científicos con clientes externos. Caracas: Fondo Editorial Fintec, 1995. p. 137-162.

WEBSTER, A. J. Bridging institutions: the role of contract research organizations in technology transfer. Science and Public Policy, v. 21, n. 2, p. 89-97, Apr. 1994.

\section{A CASE STUDY ON THE INTERACTION UNIVERSITY-INDUSTRY}

\section{Abstract}

This article presents a case of interaction university-industry considered as positive for the involved professionals - professors and researchers of the university and technical team of the company - in terms of university reserch and formation of human resources as well as to the trajectory of technological qualification of the company. More specifically, it approaches the accomplishment of a research and development project $(R \& D)$ involving professors and researchers of the Faculty of Engineering Mechanics of the State University of Campinas (FEM/Unicamp) and a multinational company of the sector of auto-parts, called, to the time, Clark Equipments, currently Eaton Trucks Corporation. The article looks for to detach aspects related to the antecedents of the interaction, as well as those related to the motivation that in the scope of the company had led to the accomplishment of the contract with the university. Search still to know the opinion of the technical team of the company, as well as of the researchers of the Unicamp, concerning its implications. The authors expects, with the presentation of this in case, to contribute for one better understanding of a present question in the current agenda of the Science, Technology and Innovation Policy: to evaluate the role can play multinationals companies for the national effort of technological development.

Key words: interaction university-industry, research \& development, science, technology and innovation policy. 